\title{
CONSECUENCIAS PROCESALES DE LA TERMINACIÓN DE LA PERSONA JURÍDICA DE DERECHO PRIVADO: REVISIÓN CRÍTICA Y PROPUESTAS DE SOLUCIÓN EN EL DERECHO CHILENO
}

\section{PROCEDURAL CONSEQUENCES OF THE TERMINATION OF LEGAL ENTITIES: CRITICAL REVISION AND PROPOSALS FOR SOLUTIONS IN CHILEAN LAW}

Ignacio Ried Undurraga*

\section{RESUMEN}

Las personas jurídicas de Derecho Privado pueden terminarse de acuerdo con las reglas de la legislación civil y comercial; sin embargo, la ley procesal civil no regula las consecuencias cuando dicha terminación ocurre mientras la persona jurídica es parte en un proceso. La doctrina y legislación comparada proponen como soluciones la sucesión procesal para algunos casos o, bien, la terminación definitiva del proceso por la inexistencia sobrevenida de un presupuesto procesal. En este trabajo se analiza la pertinencia de estas soluciones.

Palabras clave: personas jurídicas, sucesión procesal, proceso civil, interés en el proceso.

* Abogado, licenciado en Derecho de la Pontificia Universidad Católica de Chile. Máster en Derecho Penal y Ciencias Penales de la Universidad de Barcelona y Universidad Pompeu Fabra, Barcelona, España. Profesor de Derecho Procesal en la Facultad de Derecho de la Pontificia Universidad Católica de Chile y de la Facultad de Derecho de la Universidad Diego Portales. Dirección postal: Av. Andrés Bello 2711, piso 8, Las Condes, Santiago. Correo electrónico: iried@uc.cl. Artículo recibido el 5 de mayo de 2017 y aceptado para su publicación el 16 de abril de 2018. 


\begin{abstract}
Legal entities governed by private law can be terminated according to the rules of civil and commercial legislation; However, the civil procedural law does not regulate the consequences when said termination occurs while the legal person is party to a proceeding. The doctrine and comparative legislation propose as solutions the procedural succession for some cases, or, the final termination of the process for the inexistence of a procedural requisite. This paper analyzes the relevance of these solutions.
\end{abstract}

Key words: legal entities, procedural succesion, civil process, interest in process.

\title{
I. INTRODUCCIÓN
}

La pregunta que se intentará responder en este trabajo es la siguiente: c cómo debe tratarse en el proceso civil el término de la persona jurídica que es parte en él?

Para tratar de responder esta pregunta va a ser necesario revisar, en primer lugar, cómo se soluciona este problema en el Proyecto de Código Procesal Civil actualmente en trámite legislativo, y también en la legislación comparada. Aquí nos encontramos con dos posibles respuestas:

i) que el proceso debe continuar, por aplicación de la teoría de la sucesión procesal o, bien,

ii) que el proceso debe concluir, por desaparecer un presupuesto procesal, como es justamente la existencia de una de las partes.

En segundo lugar, revisaremos someramente cuáles son los mecanismos de terminación de las distintas personas jurídicas de Derecho Privado, y si las soluciones examinadas en el capítulo anterior son razonables en cada caso particular.

La Constitución Política de la República asegura ya en su primer artículo que:

"el Estado reconoce y ampara a los grupos intermedios a través de los cuales se organiza y estructura la sociedad y les garantiza la adecuada autonomía para cumplir sus propios fines específicos".

El legislador se ha encargado en los últimos años de poner a disposición de los ciudadanos distintas herramientas para simplificar la creación y el funcionamiento de nuevas formas organizativas, como sucedió con la ley $\mathrm{N}^{\circ} 20.190$ de 2007, que creó el marco normativo para las sociedades por acciones, y la ley $\mathrm{N}^{\circ} 19.857$ de 2003, que autorizó el establecimiento de 
las empresas individuales de responsabilidad limitada, ambas de gran aplicación práctica en la actualidad. Asimismo, el Ejecutivo se ha encargado de fomentar que los ciudadanos se organicen a través de formas jurídicas, como sucede con el programa "tu empresa en un día" a cargo del Ministerio de Economía, Fomento y Turismo, implementado a partir de la entrada en vigencia de la ley $\mathrm{N}^{\circ} 20.659$ de 2013, que "Simplifica el régimen de constitución, modificación y disolución de las sociedades comerciales".

El proceso jurisdiccional no se ha mantenido ajeno a este fenómeno, y así, actualmente los litigios civiles muchas veces no tienen lugar entre personas naturales, sino entre organizaciones o personas jurídicas.

$\mathrm{Al}$ igual que todas las cosas creadas por personas naturales $-\mathrm{y}$ al igual que las propias personas naturales- las personas jurídicas no tienen una duración eterna. Aunque se diga en su acto constitutivo que su plazo será "indefinido", la propia ley y los estatutos sociales contemplan variadas hipótesis de terminación. Y aun tratándose de grandes compañías de larga data, no es extraño que su vida termine para el derecho al ser fusionada o absorbida por otra gran compañía.

La terminación de las personas jurídicas es un fenómeno expresa -y a veces minuciosamente- regulado en el Derecho Privado: sus plazos, formalidades, requisitos de publicidad, consecuencias y, sobre todo, y los ulteriores responsables cuando la sociedad ya no exista.

Sin embargo, la terminación de la persona jurídica que es parte en el proceso es una situación sobre la que nuestro $C P C$ no destina ni una sola línea. Esta situación no es de sorprender si se tiene en cuenta que las formas asociativas eran la excepción al entrar en vigencia ese cuerpo legal, aunque la jurisprudencia temprana del $C P C$ da cuenta de muchos procesos en que al menos una de las partes era una persona jurídica. Esta laguna legal no tiene, por tanto, solución en la actualidad y, por lo mismo, es legítimo preguntarse: ¿qué sucede cuando una persona jurídica, que es parte en un proceso, termina? En este trabajo se formulará una propuesta normativa para responder a esta pregunta.

El PCPC sí contempla una solución a este problema, en el art. 24, dentro del capítulo 1 "De la capacidad para ser parte y de la capacidad procesal". Esta norma, intitulada "Sucesión procesal por término de la persona jurídica o de la entidad con personalidad jurídica”, dispone:

"en caso de disolución de una persona jurídica o de término, por cualquier circunstancia, de una entidad con personalidad jurídica, el proceso continuará con sus liquidadores o con quienes la sucedan en su patrimonio".

En este trabajo también se revisará la justicia y conveniencia de esta norma. 


\author{
II. LAS DISTINTAS CATEGORÍAS DOGMÁTICAS EXISTENTES \\ PARA EXPLICAR LA CONSECUENCIA DE LA TERMINACIÓN PROCESAL \\ DE LA PERSONA JURÍDICA DE DERECHO PRIVADO
}

\title{
1. La sucesión procesal
}

Quizá lo más sencillo sea comenzar analizando la norma del PCPC que sí contiene una solución para el problema planteado en este trabajo, a diferencia de la ley procesal que actualmente nos regula. Desde ya, resulta encomiable que el proyecto se haya hecho cargo del asunto. El punto a revisar es si la respuesta al problema es razonable.

El legislador del PCPC parece haber tomado abierto partido por la teoría de la "sucesión procesal" al momento de catalogar en su art. 22 varios fenómenos disímiles, como son, por un lado:

i) la muerte de una de las partes que obre por sí misma en el proceso (persona natural, se entiende, que sea además mandataria judicial),

ii) la transferencia de los derechos litigiosos por acto entre vivos y

iii) el caso que nos ocupa de terminación de la persona jurídica que es parte.

Este tratamiento conjunto no es original, en todo caso, y sigue muy de

130 cerca la propuesta del art. 47 del CPCM. Es decir, se toma una opción clara en pos de la supervivencia del proceso, aun en casos en que exista una modificación dramática y gravitante del objeto del proceso y de las partes. El PCPC asume que todos estos casos corresponden a casos de sucesión procesal, y les da un tratamiento acorde, en que el juez debe necesariamente continuar con el proceso.

Respecto del caso (i), o sea, la muerte de la parte que obra por sí misma, se trata de un evento muy poco frecuente en la práctica, ya que es ampliamente desaconsejable que el propio interesado -que al mismo tiempo es abogado habilitado- asuma su propia representación en el proceso, por razones que no es del caso entrar a analizar aquí, pero que redundan en una defensa inefectiva. El art. 22 del $P C P C$ dice:

"quedará en suspenso por este hecho el procedimiento, y se notificará a los herederos para que comparezcan a hacer uso de su derecho en un plazo igual al del emplazamiento para contestar la demanda. Si el proceso se encuentra en estado de dictarse sentencia, la suspensión se producirá después de pronunciada”.

${ }^{1}$ Sobre el concepto de sucesión procesal y su diferenciación con la "sustitución procesal”, puede consultarse la monografía de Nieva Fenoll (2004) pp. 45-55. 
Esta norma del art. 22 del $P C P C$ tiene su símil en el art. $5^{\circ}$ del $C P C$ de 1903 y el art. 47.3 del CPCM, pero ninguna de estas normas le dice al juez qué debe hacer si quien fallece es la persona natural representada en juicio por un tercero, que será por lejos el caso más común. Desde ya valga aclarar que el mandato judicial otorgado en el proceso no termina por la muerte del causante, por aplicación de los arts. 528 y 529 del Código Orgánico de Tribunales².

Distinto es el tratamiento respecto del caso (ii), o sea, la terminación de la persona jurídica que es parte en el proceso, en que el $P C P C$ ordena al juez que el juicio "continuará con sus liquidadores o con quienes la sucedan en su patrimonio", regla que se inspiró en el art. 47.3 del CPCM: "el proceso continuará con quienes la sucedan en su patrimonio".

La inclusión de estas tres hipótesis dentro de la categoría dogmática de la "sucesión procesal" no es original del $C P C M$, sino que su inspiración inmediata parece estar en la forma cómo la doctrina comparada entendió los alcances del art. $9^{\circ}$ número 7 de la hoy derogada Ley de Enjuiciamiento Civil española de 1888, norma que disponía lo siguiente: “Cesará el procurador en su representación: $7^{\circ}$ Por muerte del poderdante o del procurador". En la muy conocida monografía de Francisco Ramos Méndez de 1974 sobre la sucesión procesal, comentaba:

"la LEC, en el número $7^{\circ}$ de su artículo 9 , no prevé expresamente la sucesión en el proceso por extinción de la persona, pero denuncia uno de los efectos del fallecimiento del litigante: la cesación del procurador en la representación como consecuencia del poderdante. Dentro de esta última expresión, según común sentir de la doctrina, se incluyen tanto el óbito de las personas físicas como la extinción de las personas jurídicas, pues en ambos casos se produce el cese del representante procesal. De esta manera se enriquecen las posibilidades de aplicación de la norma. En esta hipótesis se verifican las premisas que hacen posible la aparición del fenómeno sucesorio: la extinción de una persona, ocurrida durante la pendencia de un proceso, determina la transmisión de los derechos sobre la cosa litigiosa a los herederos, y con ello la

${ }^{2}$ Romero Seguel (2011) p. 265: "la solución anterior hace una excepción a las reglas generales del Código Civil sobre terminación del contrato de mandato, atenuando el efecto que la muerte puede provocar en un proceso pendiente, sin solucionar directamente el problema de la sucesión procesal. En efecto, la posibilidad que el mandatario concluya el juicio será viable, mientras no sea necesaria la comparecencia personal del causante que le confirió el poder, como puede ser, por ejemplo, la citación a una audiencia de conciliación o de prueba. Si ello se dispone, no habrá más remedio que provocar la sucesión procesal de los herederos o el ingreso del curador de la herencia yacente, a falta de sucesores". 
necesidad de hacer entrar a éstos en el proceso. Por ello, la norma hace pesar la carga de la comparecencia sobre los herederos de la persona extinguida" .

Respecto del fallecimiento de la persona natural que obra por sí misma en el proceso, tanto la regla del art. $9^{\circ} \mathrm{N}^{\circ} 7$ de la Ley de Enjuiciamiento Civil española de 1888, como la del art. $5^{\circ}$ del $C P C$, la del art. 22 del $P C P C$ y la del art. $47.1 \mathrm{del} C P C M^{4}$ son normas "espejo" o "reflejas" de la situación que se produce para el Derecho Sustantivo o Privado: que los derechos y obligaciones del fallecido los asumirán íntegramente los herederos. En el caso chileno, está reglado en el libro tercero del Código Civil "De la sucesión por causa de muerte y de las donaciones entre vivos"; en especial en la regla del art. 1097: "los asignatarios a título universal (...) representan a la persona del testador para sucederle en todos sus derechos y obligaciones transmisibles". Operando la transmisión de los bienes y deudas del difunto en sus sucesores, parecía natural que nuestro $C P C$ de 1903 tuviera una norma en que ello tuviera un correlato al interior del proceso.

De acuerdo con el principio procesal de la litis pendente en sentido amplio, los procesos jurisdiccionales no deben verse afectados en manera alguna por situaciones o hechos extraprocesales que ocurran durante su 132 tramitación, y que muchas veces son consecuencia de la dilación inherente a todo litigio, garantizando así la eficacia de la acción ejercida ${ }^{5}$. Tratán-

${ }^{3}$ Ramos Méndez (1974) pp. 54-55. En la misma obra, p. 45, se trata de la solución del derecho alemán para la misma situación, en referencia a la norma del art. 239 de la ZPO. Sobre esta norma que, en realidad, regula una hipótesis de suspensión del procedimiento por muerte de una de las partes, se puede consultar la obra de Hess et al. (2015), pp. 466467. Señalan estos autores que frente a las hipótesis de fallecimiento de una de las partes o de pérdida de capacidad procesal de una parte, se ha entendido que "no comportan la interrupción, sino la posibilidad de suspensión si la parte está representada por un apoderado procesal. El criterio determinante de esta regulación es que debe darse una interrupción cuando, de hecho o de Derecho, nadie asume la posición de una de las partes para que pueda continuar el proceso". La ley procesal alemana regula con gran minuciosidad los trámites a que da lugar el fallecimiento de una de las partes en el proceso, que da lugar eventualmente a un incidente, pero siempre instando por su continuación. GoldSCHMIDT (2015), pp. 534538, aborda también el tema desde la perspectiva del proceso como "situación jurídica".

4 "47.1. Ocurrida la muerte o ausencia declarada de la parte que actúa por sí misma y salvo el caso de proceso relativo a derechos personalísimos, éste debe continuar con los sucesores, el cónyuge o el curador de la herencia yacente, en su caso. La contraparte podrá solicitar el emplazamiento de estas personas sin necesidad de trámite sucesorio, procediéndose en la forma prevista para la demanda y con las mismas consecuencias. Entretanto, el proceso quedará suspendido, salvo que los autos se encontraren en estado de dictar sentencia, en cuyo caso la suspensión se producirá después de pronunciada”.

${ }^{5}$ Málaga (1999), pp. 25-34. Desde el punto de vista sociológico, Luhmann (1983), p. 59 propone la diferenciación del sistema de los procesos judiciales respecto de los otros 
dose de las partes, el principio se denomina perpetuatio legitimationis, que establece la inmutabilidad en la identidad de los legitimados en el proceso al trabarse la relación procesal, sin perjuicio de los cambios que puedan producirse fuera de este. Sin embargo, se ha estimado en el ámbito doctrinal y jurisprudencial que este principio no es absoluto, que no puede llevarse hasta sus últimas consecuencias, y admite ciertas excepciones para aquellos casos en que se hace imposible o inoficioso continuar adelante con el proceso ${ }^{6}$.

Es decir, las partes en el proceso pueden contar con la expectativa de inmutabilidad de ciertas condiciones mientras dure el juicio, y a no verse perjudicadas por los cambios que experimentes ciertas realidades extraprocesales mientras el proceso se dilata. Pero esta inmutabilidad tiene excepciones, y una de ellas es justamente esta. Como anota Francisco Málaga:

“esta referencia a los daños y perjuicios es esencial a la hora de analizar los límites de la litispendencia, porque ésta protege frente a perjuicios, pero no impide, como veremos, cambios (...) que simplemente implican una disociación entre realidad y juicio que, de ser ignorada, puede redundar en la ineficacia de este último (vgr. la muerte de la parte o la transmisión de la cosa litigiosa) (...) en último término el sistema permite la ruptura de la ficción de inmutabilidad en aras de un interés distinto y prevalente"7.

Cuando fallece una persona en el proceso, el legislador parece querer que el juicio continúe, a pesar de la mutación irreversible que ha experimentado, que evidentemente es una excepción al efecto de inmutabilidad de la litispendencia. Sin embargo, y como advierte el mismo autor, que lo anterior

"no debe llevar a la conclusión de que nos encontramos ante una ruptura de la litispendencia, porque en realidad sigue existiendo

subsistemas sociales: "Vielmehr kommt es nur darauf an, eine Sinnsphäre für sich zu konstruieren, so daß selektive Prozesse der Verarbeitung von Umweltinformationen durch systemeigene Regeln und Entscheidungen gesteuert werden können, daß also Strukturen und Ereignisse der Umwelt nicht automatisch auch im System gelten, sondern erst nach Filterung von Informationen anerkannt werden" [traducción libre: "Más bien, se trata de construir para sí una esfera de significado de manera que los procesos selectivos de procesar las informaciones del entorno puedan manejarse conforme a reglas y decisiones sistémicas: que estructuras y sucesos del entorno no sean válidos automáticamente en el sistema sino que se reconozcan a partir de filtrar las informaciones"].

${ }^{6}$ Montero Aroca (2001), p. 195. También Málaga (1999), p. 224.

${ }^{7}$ Málaga (1999), p. 41. 
una proyección de la misma en los requisitos que se exigen para que la sucesión se verifique. (...) por lo que no parece descabellado considerar que esa protección es una manifestación de la litispendencia que sustituye a la dañada perpetuatio legitimationis, puesto que aquélla subsiste pese a la alteración de ésta"

Pero en el caso (i), cuando muere la parte que obra por sí misma, el legislador ha tenido el cuidado de, en primer lugar, ordenar al juez suspender el proceso para que se ponga el proceso en conocimiento de los herederos, otorgándole un plazo razonable para manifestar sus descargos, suspendiéndose en el intertanto la consecución del litigio. Y, como vimos, ni siquiera es obligatorio para el juez dictaminar la continuación del juicio con los herederos de la parte. ¿’Por qué en este caso el legislador adoptó estas precauciones? La respuesta parece estar, entre otras, en la regla del Código Civil, que consagra la posibilidad de que los asignatarios repudien la herencia, del art. 1232, siempre "dentro de los cuarenta días subsiguientes al de la demanda"; también en la regla del art. 1377:

"los títulos ejecutivos contra el difunto lo serán igualmente contra los herederos; pero los acreedores no podrán entablar o llevar 134 adelante la ejecución, sino pasados ocho días después de la notificación judicial de sus títulos”.

Aunque los plazos del Código Civil difieren con el que indica el art. $5^{\circ}$ del $C P C$, ambas normas no permiten seguir adelante el proceso contra los herederos, sino previa notificación y transcurrido un término razonable para poder defenderse o repudiar incluso la herencia, sin perjuicio de ejercer otros derechos -como el beneficio de inventario- para el que la norma civil no contempla un plazo ni oportunidad procesal para ello.

Estas reglas fueron diseñadas solo para el poco frecuente caso de que fallezca la parte que actúa por sí misma, pero parece evidente que debieran ser también aplicables para los casos más comunes cuando quien fallece es el mandante judicial que obra asistido por un abogado que no es él mismo.

Más allá de las reglas civiles y procesales recién citadas, existen razones de fondo que aconsejan esta solución procesal para el caso del fallecimiento de la persona natural que es parte en un litigio. La razón más poderosa será que tanto el juez como la contraparte ponderen y evalúen si es conveniente o necesario continuar el proceso, tal y como se concibió originalmente, en las nuevas circunstancias que se han generado a propósito del fallecimiento de la parte. El objeto del proceso quedó irremedia-

${ }^{8}$ Málaga (1999), p. 41. 
blemente determinado durante el periodo de discusión, y ciertamente la identidad de los sujetos activos y pasivos puede ser un aspecto gravitante en la estrategia escogida en un caso determinado, no solo respecto de la pretensión concreta deducida sino, también, los fundamentos jurídicos que le sirven de apoyo y la oportunidad para ejercerla. No quiero ahondar en ejemplos, pero supongamos que el objeto del juicio es la reivindicación de un inmueble, en que el demandado fallece, estando en posesión de una parte de él. Puede perfectamente el actor querer tener claridad respecto de quién será el adjudicatario y efectivo poseedor del bien a reivindicar, antes de seguir adelante con su acción. En ese caso, quizá le convenga pedir al juez que declare terminado el proceso a la espera de que concluya el proceso de partición de los bienes quedados al fallecimiento del causante.

Por la razón antes expuesta, parece impropio, como hacen las normas antes citadas del $P C P C$ y del $C P C M$, el calificar esta hipótesis como una de "sucesión procesal". Puede ocurrir que el proceso continúe con los herederos del causante que era parte en el juicio, pero puede perfectamente ello no ser así, por las razones antes apuntadas. En este sentido, ninguna de las normas que regulan este caso obliga al juez a continuar el juicio, y, por cierto, el art. $5^{\circ}$ del $C P C$ no utiliza la nomenclatura de "sucesión procesal".

Francisco Ramos Méndez, en la monografía ya citada, advierte este problema, pero lo circunscribe únicamente al caso en que desaparezca una persona jurídica. Señala:

"tratándose de personas jurídicas no puede establecerse una regla general acerca de si tal hecho origina la sucesión en el proceso o no. En unos casos, aun disueltas, subsiste la personalidad jurídica durante el período de liquidación ${ }^{9}$, por lo que continuarán como parte en el proceso pendiente hasta su terminación. En otros, puede determinar el sucesor, quién asumirá el proceso en lugar de la persona jurídica extinguida" ${ }^{10}$.

James Goldschmidt también reconocía como un caso de sucesión procesal el de "extinción de una persona jurídica"11.

De cualquier forma, el art. $24 \mathrm{del} P C P C$ reconoce esta hipótesis como una de sucesión procesal, ordenando como dijimos a que "el proceso

${ }^{9}$ La voz 'liquidación' que se emplea en este trabajo, y que usa el Código de Comercio respecto de las sociedades mercantiles, no debe ser confundida con la "nueva" liquidación concursal creada en la ley $\mathrm{N}^{\circ} 20.720$, aunque el legislador emplea exactamente el mismo término para ambos fenómenos.

${ }^{10}$ Ramos Méndez (1974), p. 17.

${ }^{11}$ Goldschmidt (1936) p. 455. 
continuará con sus liquidadores o con quienes la sucedan en su patrimonio". Al igual que sucede con la persona natural que fallece siendo parte en un proceso, esta solución es desaconsejable, por varios motivos. Una solución juiciosa habría sido permitir al juez, y sobre todo a la actora, un margen de acción dentro del proceso cuando se presente la situación de que la persona jurídica que es parte en él desaparece, incluyendo, por cierto, la posibilidad de que el juez decrete terminado el proceso por la desaparición de una de las partes, dejando intactas las acciones del actor, y mejor aún, en suspenso el plazo de prescripción.

Tal como se señaló ya, la identidad de las personas puede ser un factor gravitante dentro del objeto de un proceso, y en muchos casos puede ser aconsejable esperar a que concluya el proceso de liquidación de la persona jurídica antes de seguir adelante o, bien, de iniciar un nuevo proceso.

\section{La terminación anticipada del proceso por falta de interés o desaparición del objeto}

En el apartado anterior he expuesto las razones por las que entiendo que no todos los casos de terminación de una persona jurídica durante el proceso debieran recibir el mismo e idéntico tratamiento de "sucesión procesal". 136 Habrá casos en que lo más aconsejable -y sobre todo, la voluntad del actor así lo querrá- será continuar el proceso con "sus liquidadores o con quienes la sucedan en su patrimonio", pero en otros ello no será así.

La pregunta que surge, entonces, es si existe otra categoría dogmática para tratar este problema. Y surge la respuesta inmediata de que el proceso deba darse por terminado por la "desaparición sobrevenida del interés", siguiendo la nomenclatura de la monografía de Fernando Gascón Inchausti. Esta solución no es tan extraña ni radical como pueda parecer, y es la que se plantea, por ejemplo, para aquellos casos en que desaparece una de las partes en un juicio en que están en discusión derechos personalísimos ${ }^{12}$, como son los juicios de determinación de paternidad y maternidad y los juicios de divorcio.

En España, la obra de Fernando Gascón ha tratado este problema como un caso de "carencia sobrevenida del objeto" del proceso, en referencia al art. 22 de la Ley de Enjuiciamiento Civil española que regula este tipo de situaciones. Esto, porque si la parte demandada desaparece, fallece, se

${ }^{12}$ Romero Seguel (2011) p. 266, quien cita la regla del art. 317 del Código Civil que establece que son "legítimos contradictores" no solo los hijos contra el padre o madre sino, también, los herederos de unos y de otros; la situación en el Derecho español está tratada en GASCÓN InCHAUSTI (2003), pp. 141-147. Un análisis del tema, a propósito de las consecuencias procesales que genera la muerte de un cónyuge durante el juicio de divorcio, se encuentra en los trabajos de Gandulfo (2011) y Barría Paredes (2001). 
liquida o se disuelve, el proceso pierde interés o, bien, su objeto desaparece, ya que es insostenible o impensable seguir adelante con un litigio en que no existe un demandado contra quien sostenerlo. En gran medida, porque habrá desaparecido el patrimonio ejecutable si existe un fallo favorable.

A pesar de su obviedad, el requisito de todo proceso consistente en que existan las partes en disputa, no está recogido en ley procesal alguna. Es más: tampoco existe un control negativo cuando dicho requisito se incumple, es decir, cuando la persona que litiga desaparece. Está, efectivamente, el art. $5^{\circ}$ del $C P C$, referido a la muerte de la parte que es, además, una persona natural y que litiga por sí misma. Si echamos un vistazo a las excepciones dilatorias de nuestro $C P C$, verdadero catálogo de óbices procesales -más que verdaderas excepciones en su sentido correcto- no hay norma alguna que permita a las partes depurar el proceso de un obstáculo tan evidente como es que una de ellas sencillamente ya no existe. Igual situación se constata de las normas del proceso penal.

Esta omisión del legislador no puede ser entendida en el sentido de que la desaparición de una de las partes es un asunto irrelevante en el proceso. Al contrario, hoy existe amplio consenso en la ciencia procesal acerca de que uno de los ineludibles presupuestos procesales de todo juicio jurisdiccional contencioso es justamente la existencia de las partes en conflicto. Sin partes no puede haber proceso. Un proceso en que alguno de los sujetos -activo o pasivo- no exista deja de ser un juicio jurisdiccional para degenerar en una cosa distinta.

\section{La desaparición del proceso por falta de un presupuesto procesal}

Fue Oskar von Bülow quien acuñó el concepto de "presupuestos procesales", en su obra de 1868, creando así una hasta entonces novedosa categoría dogmática que funcionaría, al igual que una fotografía, como el "positivo" del "negativo" que serían las llamadas excepciones dilatorias ${ }^{13}$. Aunque su obra fue criticada -en algunos extremos no sin razón- la independencia de los presupuestos procesales respecto del mero control de los óbices procesales trajo una importante consecuencia: la posibilidad de que el juez apreciara de oficio su concurrencia o desaparición. En este sentido, y en lo que nos interesa en este trabajo, esta categoría independiente y más amplia, permitió incluir una serie de requisitos básicos y evidentes bajo el alero del control del juez, aunque las partes no lo reclamaran, o

\footnotetext{
${ }^{13}$ Sobre este tema, vale la pena revisar el primer capítulo sobre los orígenes históricos de las excepciones materiales y procesales (o dilatorias, para nuestro $C P C$ ) en la reciente monografía de De Miranda Vásouez (2016); también el trabajo de Romero Seguel (2004).
} 
carecieran de la excepción dilatoria para hacerlo. Lamentablemente, no es extraño encontrar cierta jurisprudencia reacia a ampliar las posibilidades de las partes de alegar ciertos obstáculos procesales al margen de las llamadas excepciones dilatorias, sin perjuicio de la norma del 303 número 6 del $C P C$, que justamente permite subsanar el proceso de todo tipo de defectos de forma que no ataquen "el fondo de la acción deducida". Pero aun en este caso, la oportunidad procesal para hacerlo es acotada a un solo momento en el proceso.

Sin embargo, en Chile la doctrina y jurisprudencia parecen recoger la situación planteada como un caso de desaparición de uno de los presupuestos procesales sin los que este no puede subsistir, adhiriendo a la doctrina de los presupuestos procesales elaborada por Oskar von Bülow ${ }^{14}$. En este caso, uno de los presupuestos del proceso es naturalmente la existencia de una parte demandada. Sin ese presupuesto -que alguna jurisprudencia ha llamado "de existencia del proceso"- no hay condiciones para formar un proceso, y lo que habría sería solo la apariencia de un juicio jurisdiccional. La teoría de los presupuestos procesales ha sido seguida en Chile por los procesalistas Carlos Anabalón Sanderson, Hugo Pereira y por Alejandro Romero Seguel ${ }^{15}$. En una sentencia de la Corte de Apelaciones de Santiago se dijo:

"son requisitos para que un juicio tenga existencia jurídica, la existencia de un juez que ejerza jurisdicción, la de las partes (...) la falta de concurrencia de alguno de ellos acarrea la inexistencia del juicio" ${ }^{16}$.

Autores como Juan Colombo, por otra parte, estiman que la existencia de las partes no es un requisito de existencia del proceso, y lo que, en realidad, sucede cuando una parte es preterida es que dicho proceso -que sí existe- le es inoponible ${ }^{17}$; otros, que se trata de un requisito de existencia de la pretensión procesal ${ }^{18}$. En la teoría de Chiovenda, del proceso como "relación jurídica", la existencia de las partes sería uno de sus elementos subjetivos ${ }^{19}$.

De cualquier forma, la solución a la que se arriba sobre la base de cualquiera de estas teorías es la misma: el proceso no puede continuar si

${ }^{14}$ Von Bülow (1964). Un análisis muy completo de la teoría y su proyección contemporánea a la luz de los principios del debido proceso se encuentra en MARINONI et al. (2010) p. 416 y ss.

${ }^{15}$ Romero Seguel (2013), pp. 5-12.

${ }^{16}$ Fallo Novoa Chevesich con Servicio de Impuestos Internos (1999), comentada en el trabajo de Romero Seguel (2001).

${ }^{17}$ Colombo (2014), p. 149.

${ }^{18}$ Avsolomovich et al. (1965), p. 33.

${ }^{19}$ Chiovenda (1922), p. 110. 
desaparece el sujeto activo o el pasivo. La pregunta, nuevamente, es si esta solución tan radical, resulta justa. Porque de lo que hablamos aquí es que el proceso termina como consecuencia obvia de la extinción de la persona jurídica que es parte en él, que es la solución opuesta a la contemplada por el $P C P C$, el $C P C M$ y la doctrina de la sucesión procesal. En la sucesión procesal el legislador obliga al juez a continuar el proceso; por el contrario, recogiendo la teoría del decaimiento del interés en el proceso por desaparición del objeto como presupuesto procesal, resultará lícito que el juez le ponga punto final para siempre, volviendo inútil el tiempo y los recursos invertidos por las partes en el proceso. Además, no debe olvidarse el "fantasma" que rodea a la extinción de la persona jurídica que es parte en el proceso, que es la comisión de un fraude o de una simulación con el objetivo de evadir las consecuencias del proceso. Sin perjuicio de ello, la solución de terminar el proceso parece justa al menos desde la perspectiva de los posibles sucesores de la persona jurídica, quienes deberán iniciar un nuevo proceso -si la entidad era actora- o ser emplazados -si era demandada- en un nuevo juicio, sin tener que asumir las consecuencias desventajosas de un proceso en curso en el cual formalmente nunca intervinieron.

Hemos llegado a un punto ciego en este trabajo: ¿debe el proceso continuar con los sucesores de la persona jurídica (si existen), o debe terminar para siempre, e iniciarse eventualmente uno nuevo en que los sucesores sean parte? Para tratar de responder esta pregunta, lo conveniente será revisar siquiera someramente cómo se pone término a las distintas formas asociativas que contempla el Derecho Privado en nuestro ordenamiento jurídico. A continuación, haré esta revisión y plantearé la respuesta que me parece más justa para cada caso.

\section{REVISIÓN CRÍTICA Y PROPUESTAS DE SOLUCIÓN EN EL DERECHO CHILENO}

Sin perjuicio de las diferencias que existen entre unas y otras, hay al menos dos causales de terminación que son comunes para todas las personas jurídicas de Derecho Privado en Chile, que son

i) la que establece el art. $26 \mathrm{~b}$ ) del decreto ley $\mathrm{N}^{\circ} 211^{20}$, que faculta al Tribunal de Defensa de la Libre Competencia a dictar una sentencia que establezca esa sanción y

${ }^{20}$ Aunque suele designársele de esta forma, la norma en vigencia es el decreto con fuerza de ley $\mathrm{N}^{\circ} 1$ de 7 de marzo de 2005, que "Fija el texto refundido, concordado y sistematizado del Decreto Ley № 211 de 1973”. 
ii) la que establece el art. $8^{\circ}$ de la Ley $\mathrm{N}^{\circ} 20.393$ sobre responsabilidad penal de las personas jurídicas, que faculta al juez penal a decretar la disolución de la persona jurídica que es imputada, como una de las penas aplicables ${ }^{21}$.

A continuación, revisaremos las particularidades de cada una.

\section{Corporaciones, asociaciones sin fines de lucro y fundaciones}

Están reguladas en el título xxxiII del Código Civil (art. 545 y ss.), modificado sustancialmente por la ley $\mathrm{N}^{\circ} 20.500^{22}$. La extinción de las corporaciones o asociaciones se remite a lo estipulado por el art. $559 \mathrm{del}$ Código Civil, que dispone las siguientes causales: por el vencimiento del plazo de su duración, si lo hubiera; por acuerdo de la asamblea general extraordinaria, cumpliendo los requisitos formales establecidos en el art. 558; por sentencia judicial ejecutoriada, en caso de estar prohibida por la Constitución o la ley o infringir gravemente sus estatutos, o haberse realizado íntegramente su fin o hacerse imposible su realización y por las demás causas previstas en los estatutos y en las leyes. Las fundaciones, por su parte, se extinguen por las mismas causales señaladas para las corpo-

140 raciones, remitiéndose al art. 599 del Código Civil, pero se suma también la del art. 564: "Las fundaciones perecen por la destrucción de los bienes destinados a su manutención".

Las corporaciones o asociaciones son la reunión de personas que se conciertan para un fin, interés o propósito común de carácter no lucrativo. Las fundaciones tampoco tienen fines de lucro, pero deben nacer con la destinación de un conjunto de bienes para un fin en particular. El art. 561 dispone:

“disuelta una corporación, se dispondrá de sus propiedades en la forma que para este caso hubieren prescrito sus estatutos; y si en ellos no se hubiere previsto este caso, pertenecerán dichas propiedades al Estado, con la obligación de emplearlos en objetos análogos a los de la institución. Tocará al Presidente de la República señalarlos".

Esta misma norma es también aplicable a las fundaciones, por remisión expresa del art. 563.

\footnotetext{
${ }^{21}$ Puga Vial (2011), p. 682.

${ }^{22}$ Un panorama de la regulación existente con anterioridad a la vigencia de esta ley se encuentra en AlesSANDRI et al. (1998), pp. 601-607.
} 
De la escueta regulación civil, parece claro que ninguna de estas personas jurídicas sin fines de lucro debe ser necesariamente liquidada por un tercero, o por sus propios miembros, sin perjuicio de que los estatutos podrían así establecerlo ${ }^{23}$. Respecto de las corporaciones y asociaciones, y siendo simplemente agrupaciones de personas en pos de un fin no lucrativo, puede darse el caso que no existan bienes que liquidar. Por lo mismo, sería inviable que el juez decrete la continuación del proceso en que estas personas jurídicas han sido partes, instando al liquidador a asumir esa representación en el litigio, si ese liquidador no fue previsto en los estatutos. Aquí estamos frente, en realidad, a extinciones instantáneas o, al menos, no sujetas al trámite de una liquidación o partición de bienes. En consecuencia, la solución aconsejable parece ser la terminación del proceso en que la corporación es parte, salvo que efectivamente se haya designado un liquidador estatutario que asuma la representación de la corporación; pero como dijimos, esta situación no es obligatoria.

Sin embargo, puede suceder que el objeto del proceso tenga relación directamente con una cosa que es de propiedad de alguna de estas personas jurídicas sin fines de lucro; en este caso, parecerá recomendable que el juez inste por la continuación del proceso invocando las teorías de la sucesión procesal. Para ello, habrá que estarse a lo que los estatutos dispongan respecto del destino de los bienes, según señala el art. 561 recién transcrito, discutiéndose en la doctrina si es lícito que los miembros de la corporación sean finalmente los destinatarios de dichos bienes ${ }^{24}$. Si es el Estado quien finalmente se apropia de los bienes pertenecientes a la corporación, asociación o fundación, podría ser recomendable que el juez decretara la terminación del proceso, y que se iniciara uno nuevo según las reglas del juicio de hacienda del art. $748 \mathrm{y}$ siguientes del $C P C$.

\section{Sociedad colectiva civil y mercantil, en comandita simple, en comandita por acciones y de responsabilidad limitada}

A diferencia de las corporaciones o asociaciones, en que el foco está en las personas que las integran, en las sociedades de personas lo gravitante es el "poner algo en común". Respecto de su disolución, se estima que para todas estas sociedades, sean civiles o mercantiles, se aplican las mismas causales: voluntad de las partes; extinción del plazo o cumplimiento de la condición fijada para que tenga fin; término de su objeto, ya sea del negocio para que se contrajo o de las cosa que conforman su objeto;

${ }^{23}$ Alessandri et al. (1998), p. 605, se refiere a un caso en que los estatutos de una corporación que había designado un "directorio liquidador".

${ }^{24}$ La discusión está recogida en Alessandri et al. (1998), p. 605. 
insolvencia por declaración judicial; falta de cumplimiento del aporte de uno de los socios por su hecho o culpa, que debe ser declarado a petición de los restantes socios; muerte de algún socio, salvo que se haya pactado o que la ley autorice a continuar con los herederos del fallecido; incapacidad o insolvencia sobreviniente de un socio; renuncia de un socio, salvo la excepción que contempla la misma ley. De las causales de terminación recién enunciadas, Luis Morand Valdivieso ${ }^{25}$ distingue algunas que operan de pleno derecho, como el cumplimiento del plazo, la muerte de un socio, de otras que requieren de la voluntad de los socios como el consentimiento unánime, renuncia de un socio y de otras que requieren de una sentencia judicial que así lo declare, como la insolvencia e incapacidad de un socio, entre otras.

Es importante, en todo caso, distinguir entre dos momentos:

i) primero, la ocurrencia de alguna de las causales de disolución enunciadas más atrás reguladas solo en el Código Civil26 y

ii) luego, el proceso a través del cual se repartirán los activos y se solucionarán los pasivos ${ }^{27}$.

Ese proceso puede ser de liquidación -si la sociedad es mercantil, art. 408 del Código de Comercio- o de partición -si es civil, art. 2115 Código Civil-. Una vez operada la disolución de la sociedad colectiva civil, hay doctrina 142 que estima que se extingue su personalidad jurídica, dando origen a una comunidad de bienes en que los ahora exsocios son $\operatorname{comuneros}^{28}$, aunque existe doctrina más moderna que ha negado esa posibilidad, y estima que cualquiera sea el caso, la personalidad jurídica siempre subsiste ${ }^{29}$ solo para

${ }^{25}$ Morand Valdivieso (2008), pp. 22-24.

${ }^{26}$ Morand Valdivieso (2008), p. 22: "las normas sobre esta materia que establece el Código Civil son muy importantes, por cuanto el Código de Comercio no contiene ninguna y se remite a ellas para las sociedades comerciales".

${ }^{27}$ JuPpet (2014), p. 519.

${ }^{28}$ Puelma AcCORSi (1998), pp. 394-395, a propósito de la diferencia entre el proceso de partición y liquidación: "la personalidad jurídica de la sociedad persiste para los efectos de la liquidación hasta el término de ésta. Por consiguiente, los bienes sujetos a liquidación los enajena el liquidador como bienes sociales sin la necesidad de autorización alguna, aunque se trate de bienes raíces y existan incapaces entre los interesados. En la partición de sociedades civiles no persiste la personalidad jurídica social. Sólo existe una comunidad regida por las reglas generales, requiriéndose de autorización judicial para enajenar bienes raíces si existen comuneros incapaces". En el mismo sentido, GuERrERo et al. (2015), p. 112: "el Código Civil entiende que de los bienes sociales se forma una comunidad entre los socios".

${ }^{29}$ Puga Vial (2011), p. 695: "respecto de otro tipo de sociedades, la supervivencia de la personalidad jurídica allende la disolución ha sido en Chile resultado de un desarrollo doctrinal que hasta hoy presenta sus dificultades dogmáticas, pues aun para las sociedades 'comerciales' y para las de responsabilidad limitada 'civiles' es posible sostener que disuelta la sociedad se extingue la personalidad jurídica. Nosotros somos de la opinión que 
efectos de ser liquidada ${ }^{30}$. Esta discrepancia doctrinal puede tener importancia para el juez que sustancia una causa en que la sociedad disuelta es parte, como se verá un poco más adelante. Más allá de la discusión acerca de la pervivencia de la personalidad jurídica de la sociedad en liquidación, para la doctrina procesal que estimamos correcta, ello no es óbice para estimar que la sociedad igualmente goza de capacidad procesal y, por lo mismo, puede perfectamente ser sujeto pasivo y activo en juicio $^{31}$. En este sentido, el Derecho procesal, por razones eminentemente prácticas, favorece la actuación en juicio de entes que para el Derecho Privado eventualmente no tengan el reconocimiento formal de personas jurídicas, estableciendo una importante distancia con la ley sustantiva de fondo en este aspecto ${ }^{32}$. De cualquier forma, la legitimación de la sociedad en liquidación -como asunto de fondo vinculado al Derecho Sustantivo debatido en el proceso- se mantiene intacta aun disuelta ${ }^{33}$.

Hay que decir, por otro lado, que la legislación privada en Chile resulta muy complicada a la hora de regular estas sociedades, habiendo subsistido a lo largo de los años un aparatoso edificio normativo al que se le agregan nuevas reglas especiales, dejando subsistentes las más antiguas en carácter de residuales ${ }^{34}$. De cualquier forma, ya sea por regulación

cualquiera sea el tipo de sociedad, la personalidad subsiste para efectos de su liquidación". La misma opinión sostiene VILLEGas (1995), pp. 198-200: “disuelta la sociedad, subsiste a los efectos de la liquidación. Como decíamos al iniciar este capítulo, la sociedad no se extingue con la disolución, sino que ésta marca el momento en que la sociedad ha sido herida de muerte, pero sobrevivirá un tiempo más o menos largo aún, que es la etapa de liquidación (...) en esta etapa final, la sociedad conserva su 'personalidad' y se rige por las reglas legales correspondientes a su tipo social”. En similares términos también LYON Puelma (2002), p. 303, citando un fallo de la Corte Suprema del año 1956.

${ }^{30}$ Iglesias et al. (2008), p. 503, quien define la liquidación como el proceso por el cual "la sociedad sigue subsistiendo con su misma personalidad jurídica, pero padece una modificación de su fin o actividad, pues abandona la explotación empresarial de su objeto social para dedicarse a una actividad meramente conservativa o liquidadora".

${ }^{31}$ Romero Seguel (2001), p. 786: “Objetivamente, no se vislumbra ninguna dificultad para reconocer capacidad procesal a una sociedad en liquidación. Es obvio que si un ente en tal estado es titular de un crédito puede cobrarlo judicialmente, y si obtiene sentencia favorable su importe entrará al proceso de liquidación. Desde el punto de vista de los socios y de los acreedores sociales, estamos seguros que ninguna objeción podrían formular al respecto".

${ }^{32}$ Gutiérrez Silva (2009), pp. 261-263; también Arancibia Mattar (1999), pp. 7-21.

${ }_{33}$ Montero Aroca (2007), pp. 175-176, refiere una sentencia del Tribunal Supremo español que desechó la excepción de falta de legitimación activa opuesta por el demandado en un juicio de cobro de letras de cambio, en que el demandante era una caja que había absorbido a la caja que era la original beneficiaria de las letras, habiendo operado la sucesión procesal.

${ }^{34}$ En este sentido, Alcalde Silva (2015), p. 320, que lo califica como "un cuadro normativo disperso, incompleto, y en muchos casos, desprovisto de una coherencia dogmática"; p. 327: "el actual diseño societario chileno lleva a preguntarse por la conveniencia de conservar 
expresa o por remisión de otros cuerpos legales, una vez disueltas las sociedades colectivas civil y mercantil entrarán necesariamente en un proceso de partición las primeras, y de liquidación las segundas ${ }^{35}$, para repartir los activos puestos en común y los pasivos generados por la sociedad durante su existencia.

En caso de que la sociedad entre en el proceso de liquidación, la solución que propongo es que el juez decrete solamente la suspensión del proceso a efectos de notificar al liquidador para que este asuma la representación de la sociedad en el proceso. Hay razones de texto poderosas que abonan esta teoría. Por de pronto, el art. 410 del Código de Comercio dispone:

"el liquidador es un verdadero mandatario de la sociedad, y como tal, deberá conformarse escrupulosamente con las reglas que le trazare su título y responder a los socios de los perjuicios que les resulten de sus operaciones dolosas o culpables",

y el art. 416 que dispone: "los liquidadores representan en juicio activa y pasivamente a los asociados". Sin embargo, despierta cierta inquietud lo dispuesto en el art. 411, que proscribe al liquidador "celebrar transacciones 144 sobre los derechos sociales, ni sujetarlos a compromiso", lo que puede limitar seriamente sus facultades en juicio, dificultad que entendemos salvados siempre que concurra la voluntad unánime de los socios.

La posibilidad de que el juicio en que es parte la sociedad disuelta continúe, actuando ahora el liquidador en su representación, soluciona solo una parte del problema. Porque lo normal es que las liquidaciones sean procesos relativamente dilatados y engorrosos, partiendo porque el legislador obliga a que se designe un árbitro que asuma dicha liquidación, el que puede ser designado por las partes en primer lugar (en los estatutos, por regla general, o en un acto posterior), o en subsidio por el juez civil, en caso de que no haya acuerdo en el nombre o los árbitros designados en el pacto social por la razón que sea no pueden asumir el cargo. Aunque esta liquidación puede efectuarse de común acuerdo entre los socios, lo común es que finalmente la liquidación la lleve un árbitro ${ }^{36}$, ya sea por falta de

el régimen supletorio de responsabilidad limitada, que remite a las reglas establecidas para las sociedades colectivas, o, al menos, de analizar hasta dónde se extiende esta supletoriedad".

${ }^{35}$ El tema está tratado en detalle en el artículo de JuPPET (2014).

${ }^{36}$ JuPPET (2014), p. 522: "No existe obligación de que el nombramiento del liquidador recaiga en uno de los socios, sino que se permite por el Código de Comercio, en su artículo 409 inciso segundo, que la designación pueda recaer en un tercero ajeno a la sociedad. La legislación chilena respeta plenamente la libertad de los socios para la realización de este nombramiento, sólo autorizando en subsidio el nombramiento judicial. Con todo, 
competencias, por la complejidad que entraña o las suspicacias naturales entre socios. Tratándose de sociedades civiles, además, la liquidación toma la forma de una partición de bienes, aplicándose en forma supletoria las reglas sobre partición de bienes hereditarios. Por lo mismo, al menos en ese caso, se dará inicio a un proceso en toda regla.

En este escenario, es poco probable -aunque no imposible- que el proceso en que la sociedad es parte concluya antes que el proceso de su propia liquidación. En este caso, como vimos, el liquidador asumirá la representación procesal de la sociedad.

La pregunta es, ¿qué sucede si la sociedad se liquida en corto tiempo, antes de concluir el proceso en que es parte? Aquí se hace muy difícil hablar de sucesión procesal, sencillamente porque la sociedad ya ha desaparecido luego de practicarse su liquidación. La solución propuesta, en este caso, es que el juez, una vez que se le comunica que la liquidación ha concluido, debe declarar terminado el proceso por desaparición de una de las partes.

Esta solución, si bien dramática en muchos casos para la contraparte - piénsese en el caso que la sociedad fue disuelta de forma fraudulentadeja a salvo las acciones para perseguir los bienes de la sociedad, en el evento que el proceso versara sobre un bien en particular; siempre que no haya operado la prescripción de la acción, como también las acciones extracontractuales por simulación o fraude relativas a la terminación ilícita, si ella tuvo lugar. Hay que señalar, sin embargo, que la legislación comercial no contempla un hito claro que marque el término de la liquidación, y en la práctica lo que ocurre es que se rinde una "cuenta final" por parte del liquidador.

En este último caso, adhiero a la solución procesal de Alejandro Romero $^{37}$ para los casos de sucesión, quien señala:

i) debe formalmente ponerse en conocimiento del juez el hecho que la sociedad ha terminado por haber concluido su liquidación,

ii) abrir un incidente al respecto, invitando a la contraparte a formular sus descargos, y eventualmente permitir que se rinda prueba al respecto y

iii) finalmente, el juez debe declarar terminado el proceso en razón de esta especial circunstancia, no bastando la mera constatación

en este punto diferimos de la legislación española, la que permite a los administradores mutar en su calidad pasando a ser liquidadores en caso de disolución de la sociedad, sólo evitándose dicho nombramiento mediante prohibición expresa de los estatutos. Es más, en mi opinión, esta pudiera ser la vía más recomendable, dado que un tercero extraño podrá cumplir con las obligaciones de auditoría con mayor objetividad, resguardando en mejor medida la fe pública que viene asociada al proceso de liquidación”.

${ }^{37}$ Romero Seguel (2011), p. 269. 
por las partes del hecho extraprocesal de que una de ellas ha desaparecido.

Por último, tratándose de una sociedad de carácter civil -al menos las colectivas- existe la teoría de que una vez disuelta esta pierde su personalidad jurídica y se crea una comunidad entre los exsocios. Para este evento, y siempre que se adhiera a esta postura, el proceso debiera concluir por la desaparición de una de las partes, aunque también podría pensarse en una solución de sucesión procesal, ordenando el juez la suspensión del proceso para notificar a los comuneros exsocios, con quienes continuará el proceso.

Un problema adicional podría presentarse en aquellos casos en que transcurra un tiempo considerable entre que la sociedad se disuelve y el liquidador es nombrado y asume el cargo. Como vimos, el proceso de nombramiento y posterior aceptación puede no estar exento de escollos y dilaciones, partiendo porque el art. $646 \mathrm{del} C P C$ se remite a las normas sobre designación de peritos para su nombramiento (art. 414 del $C P C$ ), dando origen a un procedimiento escuetamente reglado, y sobre el que los tribunales tampoco tienen mayor claridad acerca de su naturaleza, si es contenciosa o voluntaria. El problema en este caso es quién representa a la sociedad en ese tiempo intermedio, cuestión que no tiene solución en 146 la ley civil ni comercial. Parece claro que no es el liquidador o el partidor, quienes no han sido designados o no han aceptado aún el cargo. Quizá la solución justa sería entender que la sociedad, cuya personalidad jurídica permanece a pesar de estar disuelta -según la doctrina mayoritaria-debe seguir representada por sus apoderados estatutarios, al menos para los efectos de seguir adelante con los procesos judiciales en curso, en que la sociedad es parte. De lo contrario, se podría generar un efecto pernicioso en perjuicio de terceros, que de golpe pueden ver paralizado o terminado un proceso en contra de la sociedad, solo porque esta fue disuelta, y por la razón que sea, no se ha designado liquidador o partidor, o este no ha asumido el encargo.

\section{Empresa Individual de Responsabilidad Limitada}

Fue creada por la ley $\mathrm{N}^{\circ} 19.857$, y sus causales de terminación están enumeradas en su art. 15. Las causales de término de la EIRL por voluntad del empresario y por aporte del capital de la empresa individual a una sociedad, son solemnes y, por lo tanto, su incumplimiento acarrea la nulidad del acto de terminación o del aporte. Las causales que se refieren al plazo previsto en el acto constitutivo, insolvencia, y muerte del titular, requieren formalidades de publicidad, por lo que su incumplimiento acarrea la inoponibilidad de la causal de la terminación frente a terceros. Una vez que se 
cumpla con todas las formalidades, la terminación permite que se lleve a cabo la liquidación y que sea oponible a terceros ${ }^{38}$. Parece evidente que el legislador, a pesar de fomentar la creación de estas particulares "empresas de una sola persona", desconfía de ellas, al punto de rigidizar y solemnizar en extremo su terminación, previsiblemente en resguardo de los acreedores y de quienes contraten con la empresa, creando estas sanciones de nulidad e inoponibilidad. Por lo mismo, es atendible aplicar similar criterio a la hora de considerar cuáles serán los efectos procesales de su terminación.

En estos casos, lo que propongo es que el juez suspenda el proceso en que la EIRL es parte, cuando tenga noticia de que ha operado alguna causal de terminación, en el evento de que no se hubiere dado cumplimiento a las solemnidades de publicidad que establece el art. 15. Y por lo ya apuntado, parece coherente con el espíritu de esta ley que el proceso continúe con los sucesores legales de la EIRL, que normalmente será el empresario persona natural, sus herederos si este ha fallecido, o la persona a quien se aporten sus bienes. Por lo tanto, debiera operar en este caso la sucesión procesal. Hay que tener en cuenta que el art. 15, para el caso de fallecimiento del empresario, faculta a los herederos a continuar con el giro de la empresa durante un año, nombrando un gerente al efecto. En este último caso, el juez debiera ordenar que se notificara al gerente para que continúe con el proceso.

Una vez concluida la liquidación, la EIRL desaparecerá y, asimismo, desaparecerá también el proceso, según la solución ya propuesta en el apartado anterior.

\section{Sociedad anónima}

El art. 103 de la Ley de Sociedades Anónimas regula las causales de disolución, a las que pueden agregarse las siguientes:

i) la fusión de sociedades, ya sea por incorporación como por creación, regulada en el art. 99 de la misma ley y

ii) la declaración de nulidad de la sociedad, a que se refiere el inciso segundo del art. 110 de la misma ley.

Hay algunas sociedades anónimas especialmente reguladas, como los bancos, compañías de seguros, bolsas de valores y administradores de fondos de pensiones, que contemplan algunas causales adicionales de disolución y reglas especiales de liquidación, que no se tratarán en este trabajo.

$\mathrm{El}$ art. 109 de la misma ley regula los efectos de la disolución de la sociedad anónima, disponiendo que subsistirá su personalidad jurídica y, en general, pudiendo solo ejecutar los actos y celebrar los contratos que

\footnotetext{
${ }^{38}$ VÁSQUEZ (2013), pp. 134-135.
} 
tiendan a facilitar la liquidación. A pesar de compartir la nomenclatura, la doctrina estima que esta liquidación es diferente a la que opera en las sociedades de personas, en especial porque

"la responsabilidad social nunca se puede traspasar de la sociedad a los socios, como podría ocurrir en las sociedades personalistas. Es la sociedad la que se autoliquida y ella la que entrega el remanente neto a los accionistas" 39 .

Las operaciones propias de la liquidación serán, naturalmente, la realización del activo, el cobro de los créditos, el pago a los acreedores y la distribución entre los accionistas del remanente, si es que existe ese saldo una vez pagadas todas las deudas. Respecto de la sociedad anónima que es parte en un proceso, una vez declarada la liquidación, la solución más recomendable parece ser que el juez ordene la continuación del proceso con la sociedad en liquidación, operando la sucesión procesal. Y una vez concluida la liquidación -si esta concluye antes de que el proceso en que la sociedad es parte- el juez debiera declarar terminado el proceso por desaparición de una de las partes, siendo aplicable lo ya señalado en los apartados anteriores. Contra esta postura podría argumentarse que el in148 ciso segundo del art. 109 de la Ley de Sociedades Anónimas solo permite al liquidador, o a la comisión liquidadora "ejecutar los actos y contratos que tiendan directamente a efectuar la liquidación de la sociedad”, lo que interpretado restrictivamente podría entenderse que excluye el asumir el rol de parte en un proceso ya en curso.

Mención aparte merece, en todo caso, la hipótesis de fusión de una sociedad anónima ${ }^{40}$, en que lógicamente no existe un proceso de liquida-

${ }^{39}$ Puga Vial (2011), p. 680. En el mismo sentido, Ediciones y Promociones del Sur Limitada con P.E., H.A. y otros (2014): "Que en lo que atañe, ahora, a la pervivencia de la persona jurídica con posterioridad a la disolución de una sociedad anónima, resulta pertinente recordar que una vez agotada la liquidación, los socios o accionistas no son responsables de las deudas sociales, ni aunque hubieren recibido un remanente, resultando únicamente responsables del no pago a los acreedores los liquidadores, pudiendo los primeros en el caso de que juzguen negligente la forma en que se llevó a cabo la liquidación, demandar a estos últimos por su responsabilidad civil (...) Que como corolario de lo razonado precedentemente, se impone entonces reflexionar que en el caso sub lite no existiendo norma legal alguna que imponga a los demandados la continuidad legal de una sociedad disuelta y liquidada durante el año 2005, circunstancia que fue publicada en el Diario Oficial el 7 de enero de 2006, les resulta absolutamente inoponible en tal carácter el contenido de la sentencia dictada en los autos arbitrales seguidos ante el juez árbitro (...)".

${ }^{40}$ En extenso, el tema está tratado en el trabajo de Prado Puga (2008), pp. 7-27. El autor señala, en todo caso, que no solo las sociedades anónimas son susceptibles de fusionarse, sino cualquier clase de sociedad. 
ción, y así lo establece la ley ${ }^{41}$, sino que lo que ocurre es que otra sociedad anónima va a suceder a la compañía absorbida, según el concepto que entrega el art. 99 de la Ley de Sociedades Anónimas. Acota la doctrina:

"la fusión no es un fenómeno de muerte sino de supervivencia, y existiendo el denominado principio de 'continuidad legal', no es preciso pagar las deudas pendientes o distribuir los bienes de la sociedad disuelta ya que la totalidad de los activos netos y de los pasivos pasan como un todo a la sociedad fusionante" ${ }^{42}$,

lo que evidentemente constituye una poderosa garantía respecto de terceros contratantes. En este caso, parece recomendable no dar por terminado el proceso -a pesar de que, en rigor, la sociedad que era parte desapareció- sino ordenar su continuación con la sociedad absorbente, si hubo fusión por incorporación, o a la nueva sociedad creada especialmente para absorber a otras sociedades, si hubo fusión por creación. De todas formas, la fusión debe ser puesta en conocimiento del juez, y este aprobar la continuación del proceso con la parte sucesora, abriendo un incidente sobre el hecho, según la solución que propone Alejandro Romero $^{43}$, y que ya revisamos.

\section{Sociedad por acciones}

Introducida por la ley $\mathrm{N}^{\circ} 20.190$ de 2007, también conocida como Ley de Mercado de Capitales II, que agregó el párrafo 8 del libro II, título VII del Código de Comercio. Esta sociedad es considerada un híbrido, si bien tiene regulación de sociedad de personas, en lo que no está regido por la ley o sus estatutos, se le aplican las reglas de sociedad anónima cerrada, imponiéndole tener el capital dividido en acciones ${ }^{44}$. El propósito del legislador fue "fomentar la industria del capital de riesgo" y también

"ciertas ventajas de orden fiscal o tributario, porque se considera ingreso y no renta la parte de la ganancia del capital accionario percibida y que corresponda al mayor valor obtenido en la enajenación de las acciones de la misma"45.

\footnotetext{
(2008), p. 2.

${ }^{42}$ Prado Puga (2008), p. 6.

${ }^{43}$ Romero Seguel (2011), p. 269.

${ }^{44}$ Morand Valdivieso (2008), pp. 165-166.

${ }^{45}$ Sandoval López (2010), p. 226.
} 
Es necesario destacar como cualidad única de esta sociedad es que puede ser compuesta por una persona, lo que es contrario a la lógica de las personas jurídicas que impone el Código Civil, dando entrada a la sociedad unipersonal.

Esta sociedad se regirá por lo establecido en sus estatutos y por la ley que la regula, siendo supletoria la Ley de Sociedades Anónimas en lo que respecta a sociedad anónima cerrada, siempre y cuando no vayan contra la naturaleza de esta sociedad (art. 424 del Código de Comercio). En virtud de lo anterior, las causales de disolución son las mismas tratadas en el apartado anterior, con la diferencia de que en la sociedad por acciones es posible que se concentren todas las acciones en una sola mano, si el estatuto no lo prohíbe, (art. $444 \mathrm{del}$ Código de Comercio), puesto que puede ser una sociedad de una sola persona, pero existe la limitación de que estas deben ser enajenadas en el plazo que establezca el estatuto o, bien, en un año como máximo legal. Por lo mismo, respecto de estas sociedades aplica lo ya señalado respecto de las sociedades anónimas para efectos de una eventual sucesión procesal en el evento que entre en liquidación ${ }^{46}$.

\section{Comunidad}

150 Existe comunidad cada vez que varias personas tienen, sobre la totalidad de una cosa y sobre cada una de sus partes, derechos de idéntica naturaleza; es el derecho de dominio que dos o más personas tienen conjuntamente sobre la totalidad de una misma cosa y sobre cada una de sus partes. La comunidad puede originarse voluntariamente cuando se obtiene por un acto convencional entre dos o más personas de hacerse dueños del mismo bien. También puede emanar de disposiciones legales en diversos supuestos: el fallecimiento de una persona puede generar comunidad entre los herederos, sumado a la participación del cónyuge si existía sociedad conyugal; disuelta una sociedad civil hay comunidad entre los socios; se genera comunidad entre los dueños de departamentos de un edificio y los espacios comunes de este; en las sociedades de hecho, vale decir, aquellas celebradas sin las solemnidades legales correspondientes.

En cuanto a su terminación, conforme al art. 2312 del Código Civil, puede tener lugar cuando ocurre alguno de estos eventos: por la reunión de las cuotas de todos los comuneros en una sola persona; por la destrucción de la cosa común y por la división del haber común. Cuando ocurre lo primero, o sea, la reunión de todas las cuotas en una sola persona, parecerá correcto que el proceso en que la comunidad era parte continúe con la persona que se ha adueñado de la totalidad de las cuotas, dándose

${ }^{46}$ Sandoval López (2015), pp. 310-311. 
una hipótesis de sucesión procesal. Sin embargo, los otros casos parecen requerir soluciones distintas. Si se destruye la cosa en común, y más aún si la cosa común era objeto del litigio, el juez debiera declarar terminado el proceso por decaimiento del interés al desaparecer un presupuesto procesal. En caso que la cosa sea finalmente dividida o adjudicada, el proceso debiera continuar con esa persona, siempre que se haga presente esa situación en el proceso y el juez así lo apruebe.

Por último, vale la pena anotar que las comunidades no tienen personalidad jurídica, sino que, más bien, se trata de un "hecho regulado"; sin perjuicio de ello, parece no haber duda acerca de su capacidad para obrar en juicio, lo que está al menos reconocido por la Ley de Copropiedad Inmobiliaria ${ }^{47}$.

\section{Fondos de inversión privados y administradoras de fondos de inversión privados}

Especial atención merece la situación de los fondos de inversión privados, de gran aplicación práctica, en especial por los beneficios tributarios que tenían. Estos fondos no tienen personalidad jurídica, sino que son administrados por una sociedad anónima especial que los representa para todos los efectos legales, y ciertamente procesales. Respecto de la liquidación o disolución de la sociedad anónima administradora del fondo, valga lo ya dicho acerca de las sociedades anónimas.

Lo interesante es que estos fondos, a pesar de no tener existencia como persona jurídica, sí actúan para el derecho a través de su administradora. Para el proceso, quien es parte es el fondo, pero actuando siempre representado, como lo sería un incapaz. La pregunta que surge es qué sucede cuando el fondo desaparece. El art. 26 de la ley $\mathrm{N}^{\circ} 20.712$ regula el "destino de los fondos cuya administradora se disuelva o liquide", da cuenta que el fondo debe atravesar por un proceso de liquidación, que debe asumir la Asamblea de Aportantes o, en subsidio, la Superintendencia de Valores y Seguros. En este caso, el juez del proceso en que es parte el fondo, debiera notificar al ente encargado de la liquidación del mismo, para que el proceso continúe con él. Una vez liquidado, naturalmente deja de existir y, por lo tanto, el juez debiera poner término al proceso por la desaparición sobreviniente de una de las partes. Lo anterior, sin perjuicio de las acciones extracontractuales que sean procedentes contra los aportantes, la sociedad administradora o ambos, si es que la disolución fue fraudulenta o simulada solo para evadir los resultados del proceso.

${ }^{47}$ GutiÉRrez Silva (2009), p. 262. 


\section{PRocedimiento Que debe SEgUiRse ANTE LA TERminación de la Persona Jurídica de Derecho Privado en el Proceso civil}

De la exposición que he hecho hasta ahora, lo que propongo es que no existe una sola respuesta frente al problema de la desaparición de la persona jurídica que es parte en el juicio civil. Dependiendo de la persona jurídica que termine, y de las particulares reglas de disolución y su eventual liquidación o partición, será conveniente entender que estamos frente a un presupuesto de sucesión procesal o, bien, de terminación del proceso por el decaimiento de interés (o desaparición de un presupuesto procesal o de existencia del proceso, según la teoría que se siga). Pero como anunciaba al comienzo de este trabajo, ninguna de estas instituciones procesales está reconocida en la ley procesal civil chilena de 1903. Recién en el $P C P C$, inspirado en el $C P C M$, aparece una regulación para estos casos, que toma partido por la sucesión procesal en todos los casos, solución que nos parece criticable. En este trabajo propongo que estas categorías deben ser reconocidas en el proceso chileno que actualmente nos rige, siendo improcedente echar mano a instituciones afines, pero que no reflejan el contenido y consecuencias precisas de ninguna de ellas ${ }^{48}$.

La pregunta que surge inmediatamente es cuál es la "forma procedimental" que asumirá esta sucesión procesal o terminación del proceso una vez que opera en el mismo, en ausencia de una regulación expresa. La primera duda a resolver es si este asunto debe ser alegado por alguna de las partes, y luego constatado por el tribunal o, por el contrario, si el juez debe hacer un examen acerca del mismo, formar un incidente y luego emitir una decisión expresa sobre el tema. Si nos inclinamos por esta segunda opción, surge una segunda pregunta, ¿debe el juez pronunciarse en forma inmediata, o dilatar su pronunciamiento para la sentencia definitiva? Finalmente, si estimamos que este asunto debe motivar un pronunciamiento anticipado del juez, cabe preguntarse, ¿̇uál será el efecto procesal sobre todo lo obrado en el juicio, en particular, si debe entenderse anulado cuando el juicio se declara terminado?

Creo que las respuestas a algunas de estas preguntas han sido esbozadas más atrás. Respecto de lo primero, lo que he sostenido es que el asunto debe ser promovido por la vía incidental por el interesado, debiendo existir un pronunciamiento jurisdiccional expreso. Y debe ser promovido, naturalmente, antes de que el proceso termine, a riesgo de provocar la dictación de una sentencia judicial sobre el fondo perfectamente inútil, cuyo efecto de cosa juzgada no sea predicable respecto de partes existentes

${ }^{48}$ Ramos Méndez (1974), quien denunciaba la situación del Derecho español, en que el problema de la sucesión procesal se solucionaba por la vía del desistimiento de la demanda. 
para el Derecho. Aquí conviene aclarar que la solución incidental es la misma, tanto si el incidente lo promueve el actor respecto de sí mismo como si lo hace respecto del demandado o, bien, lo hace el demandado respecto de sí mismo, o este respecto del demandante. Podría pensarse que, por aplicación del principio dispositivo, bastaría con que el actor afirmara que ha desaparecido o que está en proceso de liquidación para que con ese solo antecedente el juez no tuviera más remedio que declarar terminado el proceso. Pero conviene fijarse que el $C P C$ no permite esa solución ni siquiera cuando el actor se está desistiendo de la demanda, obligando al juez a someter el desistimiento "a los trámites establecidos para los incidentes" (art. 148), cuestión que es razonable teniendo en cuenta que en muchos casos el demandado está también interesado en que se resuelva el proceso con un pronunciamiento sobre el fondo que aclare el asunto. De cualquier forma, sea que lo promueva el actor o el demandado, en todos los casos el asunto deberá ser sometido a una tramitación incidental, esto es, motivar un pronunciamiento expreso del juzgador, habiéndole otorgado la oportunidad a la contraparte de pronunciarse al respecto. No hay que perder de vista que las situaciones de sucesión procesal o de terminación del proceso por desaparición de una de las partes son supuestos excepcionales y de infrecuente ocurrencia; asimismo, puede estar siempre la sospecha de que se ha terminado a la persona jurídica en forma simulada para evadir los efectos del proceso, situación que deberá ser alegada y resuelta en el incidente que se forme, en el caso que la contraparte así lo desee.

La solución planteada es coherente con lo que propone Alejandro Romero ${ }^{49} \mathrm{y}$, asimismo, es también la sugerida por la doctrina actualizada respecto de las alegaciones sobre la ausencia de los presupuestos procesales $^{50}$, que parece plenamente coincidente con la regulación que hace el $C P C$ sobre los incidentes, que obliga a promoverlos apenas se tenga conocimiento del hecho que lo motiva, si este es sobreviniente al proceso (art. 85) y, en especial, sobre los de previo y especial pronunciamiento (art. 87 $)^{51}$.

La segunda pregunta planteada es, ¿debe este incidente ser resuelto en forma anticipada o, bien, dejarse su resolución para la sentencia definitiva? Por razones prácticas, lo recomendable será naturalmente que el juez resuelva de inmediato y en forma anticipada el incidente; es decir, que no espere a dictar sentencia sobre el fondo recién para pronunciarse

${ }^{49}$ Romero Seguel (2011).

${ }^{50}$ Marinoni et al. (2010), p. 427.

${ }^{51}$ Sobre la oportunidad procesal para promover incidentes referidos a hechos ocurridos con posterioridad a la iniciación del juicio, SAlas Vivaldi (1989), p. 71 y ss.; Stoehrel MAEs (2011), p. 148. 
sobre el tema, justamente porque la inexistencia de una de las partes, o su sucesión por una distinta, son ambos asuntos que impedirán -de ser reconocidos- un pronunciamiento sobre el fondo de la acción, tal y como fue planteada. Esta respuesta es concordante con la tramitación incidental que se propone, por aplicación de las reglas del $C P C$, aunque hay que reconocer que su aplicación por parte de los tribunales no ha sido pacífica. El art. 303 del $C P C$ contempla un catálogo más o menos laxo de excepciones dilatorias de contenido eminentemente procesal e, incluso, por aplicación de los arts. 304 y 310 del $C P C$ podrían sustanciarse como incidentes de previo y especial pronunciamiento algunas alegaciones referidas al fondo del asunto, como son la transacción, la cosa juzgada o la prescripción. Por lo mismo, puede hablarse de un proceso que tiende a la depuración anticipada de vicios procesales, sin tener que esperar a la dictación del fallo de fondo, salvo que se trate de procedimientos especiales, como el sumario, que obliga a promover todos los incidentes en la misma audiencia de contestación de la demanda, y al juez a resolverlos en la sentencia definitiva (art. 690). La duda, acerca del mejor momento procesal para resolver este asunto, en todo caso, es válida, teniendo en cuenta que el mero reconocimiento de la categoría "presupuestos procesales" ha sido un tema espinudo en la doctrina procesal, llegando a negarse su procedencia, por ejemplo, por parte de James Goldschmidt, quien alegaba que se trataba de una categoría inútil, ya que en realidad se trataba de pronunciamientos sobre la sentencia de fondo y que, por lo mismo, no ameritaba un pronunciamiento procesal independiente $\mathrm{o}$, bien, tendiendo la doctrina actual a reformular su contenido ${ }^{52}$.

Finalmente, cabe preguntarse respecto de los efectos que acarrea en el proceso la declaración de sucesión procesal y de terminación de la persona jurídica que litiga. Respecto de la sucesión, parece claro que el efecto que se pretende evitar es justamente la terminación del proceso, haciendo permeable el juicio a una realidad material extraprocesal. En palabras de Ramos Méndez:

“en cuanto parte, el sucesor tendrá todas las expectativas y cargas, facultades y poderes, que corresponden a la posición en la que ha subentrado. Ahora bien, el proceso deviene sin detenerse en su camino hasta la sentencia, sin retroceder en su curso, por lo que las oportunidades procesales que adquiere el sucesor son las que no están precluidas. Esto significa también que la sucesión puede ocurrir en cualquier momento de la duración del proceso, mientras está vivo, por lo que habrá que tener presente en cada hipótesis

${ }^{52}$ Marinoni et al. (2010), p. 445; Goldschmidt (2015), p. 50. 
las peculiares condiciones de existencia del proceso para dar a la sucesión el tratamiento adecuado" ${ }^{53}$.

Esta solución está en la línea de una institución procesal afín que sí está regulada en el $C P C$, como es la intervención de los terceros, que pueden participar en el proceso, pero entendiéndose "que acepta todo lo obrado antes de su presentación, continuando el juicio en el estado en que se encuentre" (art. 22). Respecto de la declaración de terminación de la persona jurídica, ello dará lugar a la finalización del proceso. ¿Es inútil o nulo todo lo obrado en él? Frente a la falta de regulación en el $C P C$, perfectamente la parte que promueve este incidente podría darle el contenido de nulidad procesal, recurriendo a las categorías sí regladas en la ley procesal civil chilena y, en este entendido, habría que estarse a sus efectos, si el juez así lo declara. Parece claro que el perjuicio alegado sería solo reparable mediante la nulidad procesal, a falta de un remedio ad hoc en la ley. En mi opinión, lo correcto es que el juez emita una resolución que declare terminado el proceso cuyo efecto es simplemente que se pierde o se vuelve inútil todo lo obrado en él, por la sencilla razón de que una de las partes a quien debía afectar la sentencia de fondo que se iba a dictar, ha desaparecido. Esto deja a salvo las futuras pretensiones que puedan hacerse valer en otros procesos, siempre que los plazos de prescripción de la acción no estén cumplidos y siempre que sea viable dirigir la acción ya ejercida en contra de un tercero distinto a la parte desaparecida; o viceversa: siempre que en el futuro sea posible identificar un nuevo legitimado activo interesado en ejercer dicha acción terminada por la desaparición del actor.

De lo explicado hasta ahora, es posible ponerse en la hipótesis en que coexista un proceso de partición o de liquidación de una persona jurídica, con un proceso en que dicha sociedad -ahora disuelta y en proceso de extinguirse- es parte. Como hemos dicho, en muchos casos el proceso en que la sociedad es parte deberá continuar con el nuevo representante de la sociedad, el partidor o el liquidador. Esta coexistencia de procesos puede entrañar algunas dificultades, en especial, si el objeto de ese otro juicio incide justamente en la determinación del activo de la sociedad en liquidación o en la determinación del carácter de socio de una determinada persona, entre otros casos que se pueden pensar. Es decir, aquellos casos en que lo que deba fallarse en un proceso sea un antecedente lógico y previo para el proceso de liquidación; o lo que es lo mismo, aquellos casos en que uno sea prejudicial ${ }^{54}$ al otro.

${ }^{53}$ Ramos Méndez (1974), p. 123.

${ }^{54}$ Rivero Hurtado (2016), p. 116: "la prejudicialidad no es sino un vínculo jurídico de dependencia, subordinación o condicionamiento entre los diversos derechos, situaciones o 
Respecto del proceso de liquidación, no existe norma especial alguna que regule el problema. En materia de partición, el art. 1330 del Código Civil establece que son competencia de la justicia ordinaria -y no del partidor- los juicios sobre "derechos a la sucesión por testamento, abintestato, desheredamiento, incapacidad o indignidad", regla que no nos sirve cuando se trata de aplicar las reglas de la partición respecto de la sociedad disuelta. El art. 1331, a su turno, es explícito en disponer que es competencia de la justicia ordinaria -y no del partidor-

"las cuestiones sobre la propiedad de objetos en que alguien alegue un derecho exclusivo y que en consecuencia no deban entrar en la masa partible",

señalando que "no se retardará la partición por ellas", pudiendo sin embargo suspenderse sólo "cuando recayeren sobre una parte considerable de la masa partible", y siempre que los asignatarios a quienes corresponde más de la mitad de la masa así lo solicitaren ${ }^{55}$.

En estos casos, los remedios procesales que establece la ley corresponden a la cosa juzgada y la litispendencia, debiendo desecharse desde ya la posibilidad de acumular los procesos, si entendemos aplicables por 156 analogía las normas de los arts. 1330 y 1331 del Código Civila la liquidación. La cosa juzgada sería una solución viable en la medida que el proceso en que la sociedad es parte ya se encuentre fallado por sentencia firme; pero en este caso la verdad es que no tiene sentido hablar de sucesión procesal, ya que el proceso estará terminado. Por lo mismo, parece ser que la única vía de remediar este problema de prejudicialidad será la alegación de litispendencia en el proceso de liquidación o de partición. Esta solución, sin embargo, tiene dos dificultades. La primera, es que la liquidación no es propiamente un proceso jurisdiccional con etapas claras para efectuar este tipo de alegaciones, sino, más bien, una serie de gestiones gerenciales para el pago de los pasivos y repartición de los activos ${ }^{56}$. Pero aun cuando el liquidador admitiera que una litispendencia es alegable, nos encontra-

relaciones jurídicas regladas por el ordenamiento sustantivo, cuya explicación se encuentra, como se ha visto, en la estructura propia de las normas jurídica. En el plano procesal, a nuestro juicio, este vínculo de dependencia se presenta o manifiesta como un antecedente lógico-jurídico controvertido que, pudiendo por sí mismo constituir objeto autónomo de un proceso, debe ser resuelto o tenido en consideración por el juez -en caso que ya exista sentencia firme- en forma previa a la decisión del fondo del asunto en tanto su decisión condiciona o determina, a lo menos, potencialmente, el sentido de la sentencia que debe dictarse concediendo o denegando la tutela jurídica solicitada".

${ }^{55}$ Rivero Hurtado (2016), pp. 444-452.

${ }^{56}$ JupPet (2014). 
remos con el escollo de que nuestros tribunales interpretan este instituto restrictivamente, acogiendo sólo en contados casos la "litispendencia por conexidad" y "por prejudicialidad" ${ }^{7}$, yendo más allá de la comprobación del requisito de la triple identidad legal del art. 177 del $C P C$, que es justamente el ejercicio que el tribunal deberá efectuar en este caso.

\section{Conclusiones}

1. La ley procesal civil vigente no regula cuáles son las consecuencias ni el tratamiento procesal de la terminación de una persona jurídica que es parte en un proceso. En el Proyecto de Código Procesal Civil en tramitación, y en la legislación y doctrina comparadas, es posible encontrar soluciones para este problema, inclinándose, en algunos casos, por la teoría de la sucesión procesal y, en otros, por la terminación del proceso por desaparecer un presupuesto procesal en forma sobrevenida.

2. Cada una de las distintas formas asociativas que reconoce el Derecho Privado chileno admite distintas causales, formas y procesos de terminación, pudiendo distinguirse algunos casos en que el ente se extinguirá en forma instantánea y, en otros, dará lugar a un proceso de liquidación, o partición, o dará origen a una comunidad o, bien, continuarán sus derechos y obligaciones a través de una sociedad distinta, en casos de fusión. Por lo tanto, la consecuencia en el proceso civil para cada una de estas formas debiera ser también distintas, y analizadas caso a caso: en algunos, será aconsejable la continuación o sucesión en el proceso y, en otros, su terminación por la desaparición sobrevenida de una de las partes.

3. La realidad extraprocesal, como es la terminación de una sociedad de acuerdo con el Derecho Privado, evidentemente debe permear al proceso civil, haciendo una excepción al principio de perpetuatio legitimationis, en lo que respecta a la identidad de las partes. Pero para ello se propone que sea el juez quien debe formar un incidente cuando ello ocurra, debiendo pronunciarse expresamente acerca de las consecuencias procesales.

\section{Bibliografía CITADA}

Alcalde Silva, Jaime (2015). "Hacia una modernización del régimen de la sociedad de responsabilidad limitada", en María Fernanda Vásouez, y José

${ }^{57}$ Ried UndurRaga (2015), pp. 231-238. 
Miguel Embid (dirs). Modernización del derecho societario. Santiago: Editorial Thomson Reuters.

Alessandri, Arturo, Manuel Somarriva y Antonio Vodanovic (1998). Tratado de Derecho civil, Partes preliminar y general. Tomo I. Santiago: Editorial Jurídica de Chile.

Arancibia Mattar, Jaime (1999). "Capacidad procesal de los cuerpos intermedios que carecen de personalidad jurídica”. Gaceta Jurídica. N $^{\circ} 233$. Santiago.

Avsolomovich, Alex, Germán LüHrs y Ernesto Noguera (1965). Nociones de Derecho Procesal. Valparaíso: Editorial Jurídica de Chile.

Barría Paredes, Manuel (2001). "La muerte de uno de los cónyuges pendiente el juicio de divorcio". Estudios de Derecho Civil, $\mathrm{N}^{\circ} 4$. Santiago.

Chiovenda, Giuseppe (1922). Principios de Derecho procesal civil. Madrid: Editorial Reus S. A.

Colombo, Juan (2014). Los actos procesales. Santiago: Editorial Jurídica de Chile. Tomo I.

De Miranda Vásquez, Carlos (2016). Las excepciones materiales en el proceso civil. Barcelona: J. M. Bosch Editor.

Gandulfo, Eduardo (2011). "Presupuestos procesales y su decaimiento en los juicios personalísimos. La capacidad procesal en el caso "Quezada Arias con Farías Lauri". Revista de Derecho de la Universidad Católica del Norte, año $18, \mathrm{~N}^{\circ} 1$. Antofagasta.

Gascón Inchausti, Fernando (2003). La terminación anticipada del proceso por desaparición sobrevenida del interés. Madrid: Editorial Civitas.

Goldschmidt, James (1936). Derecho procesal civil. Barcelona: Editorial Labor.

Goldschmidt, James (2015). Derecho, derecho penal y proceso III, El proceso como situación jurídica. Una crítica al pensamiento procesal. Madrid: Editorial Marcial Pons.

Guerrero Valenzuela, Roberto y Matías Zegers Ruiz-Tagle (2014). Manual sobre Derecho de Sociedades. Santiago: Ediciones Universidad Católica de Chile.

GutiérRez Silva, José Ramón (2009). "El presupuesto procesal de la capacidad en las personas jurídicas, en especial las de derecho público". Revista Chilena de Derecho, vol. $36 \mathrm{~N}^{\circ}$ 2. Santiago.

Hess, Burkhard y Othmar JaueRnig (2015). Manual de Derecho procesal civil. Madrid: Editorial Marcial Pons.

Iglesias, Juan Luis y Javier GarCía de EnTERRÍA (2008). "La disolución y liquidación de las sociedades mercantiles”, en Aurelio MenÉndez (coord.). Lecciones de Derecho Mercantil. Madrid: Editorial Thomson Civitas.

Juppet Ewing, María Fernanda (2014). "Liquidación de una sociedad mercantil", Revista Actualidad Jurídica de la Universidad del Desarrollo, $\mathrm{N}^{\circ} 30$. Santiago.

Luhmann, Niklas (1983). Legitimation durch Verfahren. Frankfurt: Suhrkamp Taschenbuch Wissenschaft.

Lyon Puelma, Alberto (2002). Personas jurídicas. Santiago: Ediciones Universidad Católica de Chile. 
Málaga, Francisco (1999). La litispendencia. Barcelona: Bosch Editores.

Marinoni, Luis Guilherme, Álvaro Pérez Ragone y Raúl Núñez OJeda (2010). Fundamentos del proceso civil. Hacia una teoría de la adjudicación. Santiago: Editorial Legal Publishing.

Montero Aroca, Juan (2007). De la legitimación en el proceso civil. Barcelona: Editorial Bosch S. A.

Morand Valdivieso, Luis (2008). Sociedades. Santiago: Editorial Jurídica de Chile.

Nieva Fenoll, Jordi (2004). La sustitución procesal. Madrid: Editorial Marcial Pons.

Prado Puga, Arturo, (2008). "Análisis doctrinal y jurisprudencial de la figura de la fusión”. Gaceta Jurídica. N 340. Santiago.

Puelma Accorsi, Álvaro (1998). Sociedades. Segunda edición actualizada. Santiago: Editorial Jurídica de Chile.

Puga Vial, Juan Esteban (2011). La sociedad anónima y otras sociedades por acciones en el derecho chileno. Santiago: Editorial Jurídica de Chile.

Ramos Méndez, Francisco (1974). La sucesión procesal. Estudio de los cambios de parte en el proceso. Barcelona: Editorial Hispano Europea.

Ried UndurRaga, Ignacio (2015). "Tres cuestiones sobre la excepción de litispendencia en el proceso civil chileno", Revista de Derecho de la Pontificia Universidad Católica de Valparaíso. Vol. xLV, 2015. Valparaíso

Rivero Hurtado, Renée (2016). La prejudicialidad en el proceso civil chileno. Santiago: Editorial Thomson Reuters.

Romero Seguel, Alejandro (2001). "El control de oficio de los presupuestos procesales y la cosa juzgada aparente. La capacidad procesal". Revista Chilena de Derecho, Vol. $28 \mathrm{~N}^{\circ}$ 4. Santiago.

Romero Seguel, Alejandro (2004). "La falta de jurisdicción y su denuncia en el proceso: las excepciones procesales y materiales", Revista Chilena de Derecho, vol. 31. Santiago.

Romero Seguel, Alejandro (2011). "La sucesión procesal o cambio de partes en el proceso civil", Revista Ius et Praxis, año 17, $\mathrm{N}^{\circ} 1$. Talca.

Romero Seguel, Alejandro (2012). "La disolución judicial de la sociedad anónima cerrada: aspectos procesales". Cuaderno de Extensión Jurídica $\mathrm{N}^{\circ}$ 22, Santiago: Universidad de Los Andes. Facultad de Derecho.

Romero Seguel, Alejandro (2013). Curso de Derecho procesal civil. Los presupuestos procesales relativos al órgano jurisdiccional y a las partes. Santiago: Editorial Thomson Reuters.

SALAS Vivaldi, Julio (1989). Los incidentes y en especial el de nulidad procesal. Santiago: Editorial Jurídica de Chile.

Sandoval López, Ricardo (2010). Derecho comercial. Tomo I. Volumen II. Santiago: Editorial Jurídica de Chile.

SAndoval López, Ricardo (2015). "Formación, funcionamiento y disolución de sociedades por acciones y sociedades anónimas", en María Fernanda VÁs- 
QuEZ y José Miguel EmbID (dirs), Modernización del derecho societario. Santiago: Editorial Thomson Reuters.

Stoenrel Maes, Carlos Alberto (2011). De las disposiciones comunes a todo procedimiento y de los incidentes. $6^{\mathrm{a}}$ ed. Santiago: Editorial Jurídica de Chile.

VÁsquez Palma, María Fernanda (2013). Sociedades. Santiago: Editorial Thomson Reuters.

Villegas, Carlos Gilberto (1995). Tratado de las sociedades. Santiago: Editorial Jurídica de Chile.

Von BÜlow, Oskar (1964). La teoría de las excepciones procesales y los presupuestos procesales. Madrid: Editorial EJEA.

\section{Jurisprudencia citada}

Novoa Chevesich con Servicio de Impuestos Internos (1999): Corte de Apelaciones de Santiago, 24 de mayo de 2000, NIC 2540-1999.

Empresas Ariztía S. A. (2013): Tribunal Constitucional, de 20 de agosto de 2013 (requerimiento de inaplicabilidad por inconstitucionalidad), rol 23812012.

Ediciones y Promociones del Sur Limitada con P. E., H. A. y otros (2014): Corte de Apelaciones de Santiago, de 13 de octubre de 2014 (casación en la forma y apelación), rol 9387-2013.

\section{Normas citadas}

Constitución Política de la República.

Código Orgánico de Tribunales.

Código Civil.

Código de Comercio.

Código de Procedimiento Civil.

Ley de Enjuiciamiento Civil española de 1888.

Código Procesal Civil modelo para Iberoamérica del Instituto Iberoamericano de Derecho Procesal.

Proyecto de Código Procesal Civil, Boletín N ${ }^{\circ}$ 8197-07.

Ley $\mathrm{N}^{\circ} 3.918$ de sociedades de responsabilidad limitada. Diario Oficial, de $14 \mathrm{de}$ marzo de 1923.

Ley N 18.046 de sociedades anónimas. Diario Oficial, de 22 de octubre de 1981.

Ley $\mathrm{N}^{\circ} 19.857$, que autoriza el establecimiento de empresas individuales de responsabilidad limitada. Diario Oficial, de 11 de febrero de 2003.

Decreto con fuerza de ley $\mathrm{N}^{\circ} 1$ de 7 de marzo de 2005, que "Fija el texto refundido, concordado y sistematizado del Decreto Ley N 211 de 1973". 
Ley $\mathrm{N}^{\circ}$ 20.190, que introduce adecuaciones tributarias e institucionales para el fomento de la industria de capital de riesgo y continúa el proceso de modernización del mercado de capitales. Diario Oficial, de 5 de junio de 2007.

Ley $N^{\circ} 20.393$, que establece la responsabilidad penal de las personas jurídicas en los delitos de lavado de activos, financiamiento del terrorismo y delitos de cohecho que indica. Diario Oficial 2 de diciembre de 2009.

Ley $\mathrm{N}^{\circ} 20.500$, sobre asociaciones y participación ciudadana en la gestión pública. Diario Oficial, 16 de febrero de 2011.

Ley $\mathrm{N}^{\circ} 20.659$, que simplifica el régimen de constitución, modificación y disolución de las sociedades comerciales. Diario Oficial, de 8 de febrero de 2013.

Ley $\mathrm{N}^{\circ} 20.712$ sobre administración de fondos de terceros y carteras individuales y deroga los cuerpos legales que indica. Diario Oficial, 7 de enero de 2014. 